\title{
A DIMENSÃO SOCIOTERRITORIAL NA INTERFACE ENTRE A JUSTIÇA DA INFÂNCIA E JUVENTUDE E A ASSISTÊNCIA SOCIAL EM SÃO PAULO
}

The socio-territorial dimension to the interface between the Justice for Children and Youth and the Social Assistance in São Paulo

\author{
Eunice Fávero ${ }^{1}$ \\ Janaina Aparecida Dias ${ }^{2}$ \\ Samira Leinko Matsuda Raphael ${ }^{3}$ \\ Vilma Setsuko Noro dos Santos ${ }^{4}$
}

\section{Resumo}

Este texto apresenta apontamentos sobre a operacionalização da Justiça da Infância e Juventude, com base em processos que envolvem a destituição do poder familiar, e a dimensão socioterritorial da Política de Assistência Social no município de São Paulo. Nesse foco, reporta aspectos da realidade social da população envolvida nessas ações, índices de vulnerabilidade social no município e a distribuição desigual e insuficiente de equipamentos e serviços de proteção social, básica e especial.

Palavras-chave: Justiça da Infância e Juventude. Proteção Social. Dimensão Socioterritorial. Vulnerabilidade Social.

\begin{abstract}
This paper presents notes on the operationalization of Justice for Children and Youth, based on processes that involve the removal of family power, and the socio-territorial dimension of the Social Assistance Policy in São Paulo. In this focus, it reports aspects of the social reality of the people involved in these actions, indices of social vulnerability in the municipality and the unequal and insufficient distribution of equipments and services of social, basic and special protection.
\end{abstract}

Keywords: Justice for Children and Youth. Social Protection. Socio-territorial Dimension. Social Vulnerability.

\footnotetext{
${ }^{1}$ Assistente social. Doutora em Serviço Social. Pesquisadora da área Judiciária. Docente e líder do NEP Políticas e Práticas Sociais com Famílias (NEPPSF), do Mestrado em Políticas Sociais/UNICSUL-SP. Telefone: 11 33853015. E-mail: eunicetf@gmail.com.

${ }^{2}$ Assistente Social. Pesquisadora do NEPPSF.

${ }^{3}$ Assistente Social. Mestre em Políticas Sociais. Pesquisadora do NEPPSF.

${ }^{4}$ Assistente Social. Pesquisadora do NEPPSF.

A Pesquisa "Realidade social, direitos e perda do poder familiar: desproteção social x direito à convivência familiar e comunitária" (PESQUISA DPF. NEPPSF/UNICSUL, 2014), da qual este artigo é um dos produtos, contou também com as pesquisadoras/co-autoras: Andrea Svicero, Celina Campos, Fabiana Brígido, Miriam Vega da Silva.

Serv. Soc. \& Saúde, Campinas, SP v. 13, n. 2 (18) p. 169-188 jul./dez. 2014 ISSN 1676-6806
} 


\section{INTRODUÇÃO}

Este texto aborda um dos aspectos trabalhados em pesquisa sobre a destituição do poder familiar, sistematizada a partir de autos processuais que tramitaram no segundo semestre do ano de 2010 em seis das Varas da Infância e Juventude de São Paulo (VIJs), capital, representativas regiões do município (PESQUISA DPF, 2014).

Tomando como fonte documentos constituintes desses autos, dentre eles, relatórios da equipe interprofissional, manifestações do Ministério Público e de defensores, sentenças judiciais, foram localizados 96 processos com sentenças de destituição do poder familiar ${ }^{5}$, envolvendo 121 pessoas: em 66 apenas a mãe, em cinco apenas o pai, em 25 o pai e a mãe. O relatório final da pesquisa revela que essa população, em sua totalidade, vivencia precárias condições sociais, com ausência de acesso a direitos sociais em todo o percurso de vida, incluindo gerações familiares anteriores, expondo em grande parte das situações a degradação da vida humana, em que a vivência em situação de rua e a dependência química com uso abusivo de drogas - com destaque para o crack - se sobressaem. A desproteção social, particularmente no que se refere à Assistência Social (um dos focos da pesquisa), se evidencia, revelando, também, a desarticulação entre a implementação e operacionalização dessa política de proteção social e a operacionalização da Justiça da Infância e da Juventude.

A busca da proteção prioritária à criança - ser não autônomo e em desenvolvimento, inserindo-a em unidades de acolhimento institucional/abrigo ou em famílias substitutas mediante adoção, deixa de lado, muitas vezes, a necessária atenção à família de origem, como se ao 'adentrar' ao Judiciário, a invisibilidade dessa família se acentuasse, como se não fosse composta por seres humanos 'de direitos'. A ausência de articulação entre a ação do Judiciário e a gestão do território no que se refere especialmente aos equipamentos de proteção social da Assistência Social é um dos pontos que marcam o estudo realizado, na medida em que a própria abrangência de uma Vara da Infância e da Juventude é, historicamente, muito diferente da abrangência dos distritos e subprefeituras do município, o que dificulta ou mesmo inviabiliza ações interdisciplinares e intersetoriais com vistas a assegurar alguma forma de proteção

\footnotetext{
${ }^{5}$ Esse número não necessariamente coincide com o total de sentenças de destituição do poder familiar em cada uma das VIJs, pois em algumas delas existiam autos que estavam em outra instância, devido a recursos judiciais.

Serv. Soc. \& Saúde, Campinas, SP v. 13, n. 2 (18) p. 169-188 jul./dez. 2014 ISSN 1676-6806
} 
social às famílias, incluindo aqui o direito da criança e do adolescente à convivência familiar e comunitária, preferencialmente na família de origem.

Assim, de acordo com o que foi constatado pela referida pesquisa, busca-se neste texto oferecer alguns elementos para a reflexão sobre a importância da dimensão socioterritorial para a efetivação da necessária intersetorialidade entre Justiça da Infância e Juventude e Política de Assistência Social.

\section{A Política de Assistência Social e o território}

A organização da política de assistência social conforme a Lei Orgânica de Assistência Social (LOAS) tem como diretriz a descentralização política e administrativa, a qual pressupõe o reconhecimento das particularidades e desigualdades socioterritoriais presentes nas mais diversas regiões do país e a relevância das necessidades na heterogeneidade do espaço constitutivo das cidades, ou seja, do território onde vivem os usuários da assistência social.

A Norma Operacional Básica do Suas/2005 (atualizada pela NOB/Suas/2012) prevê que

[...] as ações públicas da área da assistência social devem ser planejadas territorialmente tendo em vista a superação da fragmentação, o alcance da universalidade de cobertura, a possibilidade de planejar e monitorar a rede de serviços, realizar a vigilância social das exclusões e estigmatizações presentes nos territórios de maior incidência de vulnerabilidade e carecimentos (BRASIL, 2005, p. 53).

A NOB/Suas/2012 reafirma a territorialização entre as diretrizes estruturantes da gestão e, ao dispor sobre a Política de Assistência Social como instrumento de planejamento estratégico, destaca em sua estrutura o diagnóstico socioterritorial, o qual "tem por base o conhecimento da realidade a partir da leitura dos territórios, microterritórios ou outros recortes socioterritoriais que possibilitem identificar as dinâmicas sociais, econômicas, políticas e culturais que os caracterizam, reconhecendo as suas demandas e potencialidades" (BRASIL, 2012, p. 25).

Para compreensão do conceito de território, tomam-se como suporte estudos de Koga (2003), que o descreve como um instrumento para análise da realidade com vistas à produção e execução das políticas públicas de inclusão social, que objetivem a redistribuição de bens sociais e o enfrentamento das desigualdades sociais. 
Partindo da perspectiva dessa autora, o território é o elemento essencial para a efetivação da Política de Assistência Social, para o acesso à proteção social nos seus dois níveis - básica e especial - conforme definido por essa política.

Para Koga (2003, p. 33), o território representa:

O chão do exercício da cidadania, pois cidadania significa vida ativa no território, onde se concretizam as relações sociais, as relações de vizinhança e solidariedade, as relações de poder. É no território que as desigualdades sociais tornam-se evidentes entre os cidadãos, as condições de vida entre moradores de uma mesma cidade mostram-se diferenciadas, a presença/ausência dos serviços públicos se faz sentir e a qualidade destes mesmos serviços apresenta-se desigual.

A perspectiva socioterritorial contemplada na Política Nacional de Assistência Social - PNAS/2004 visa à construção de uma política de proteção à população em situação de vulnerabilidade e risco social e, como uma das estratégias, foram concebidos os Centros de Referência de Assistência Social (CRAS) (BRASIL, 2005).

O CRAS responsabiliza-se pela Proteção Social Básica e, tendo-a por referência, deve efetivar "o serviço de acompanhamento de grupos territoriais até 5.000 famílias em situação de vulnerabilidade, em núcleos de até 20.000 habitantes" (BRASIL, 2005, p. 19). Esses grupos familiares, ainda segundo a NOB/SUAS (ibid., p. 20), são as famílias de referência que vivem em "áreas caracterizadas como de vulnerabilidade, definidas a partir de indicadores estabelecidos por órgão federal, pactuados e deliberados".

Os Centros de Referência Especializados de Assistência Social (CREAS), também concebidos pela PNAS, por sua vez, inserem-se na Proteção Social Especial, a qual deve ser destinada a famílias e indivíduos cujos direitos tenham sido ameaçados ou violados por meio de abandono, situação de rua, trabalho infantil, violência física e/ou psicológica, abuso sexual, rompimento de vínculos familiares, entre outros (BRASIL/ PNAS, 2005). É de natureza pública, estatal, e no desenvolvimento de suas atividades, além de oferta de serviços, é fundamental a articulação no território com serviços da rede socioassistencial e o sistema de garantia de direitos. Em metrópoles, como é o caso de São Paulo, o parâmetro de referência para a implantação do CREAS é um a cada 200 mil habitantes (BRASIL, 2011).

De acordo com as diretrizes da Política de Assistência Social, os CRAS e CREAS não sãos propostos para serem apenas mais um equipamento público que está no território. Os trabalhadores que ali operacionalizam a Política de Assistência Social 
devem compreender o território como sendo o chão da cidadania e o espaço de vida, onde se formam as relações sociais e as políticas sociais, as quais permitem sua identificação e atuação por meio da articulação da rede socioassistencial presente nesse território.

De acordo com a NOB/SUAS/2005, "a rede se configura como um conjunto integrado de ações de iniciativa do governo ou da sociedade que oferta e operacionaliza serviços, projetos, benefícios, programas, sob a articulação das unidades de proteção social básica ou especial e por níveis de complexidade" (BRASIL, 2005, p. 22).

A articulação da assistência social com a rede socioassistencial permite evidenciar sua territorialização, ou seja, sua atuação dentro do território de forma a assegurar a proteção social, atender a população conforme suas necessidades, viabilizar o acesso aos serviços, projetos e programas sociais, concretizar as ações intersetoriais e fortalecer a Política de Assistência Social.

Nesse cenário também se inserem as Varas da Infância e da Juventude, com prestação jurisdicional estreitamente relacionada à rede socioassistencial, uma vez que o acesso de famílias de crianças e adolescentes que figuram nos autos processuais a recursos dessa natureza pode contribuir para a garantia do direito à convivência familiar e comunitária, conforme disposto no Estatuto da Criança e do Adolescente (BRASIL, 2010). Assim, a reflexão sobre a interface da Justiça da Infância e da Juventude com as políticas sociais necessita, dentre outros elementos, ser permeada por dados socioterritoriais que caracterizem o município, particularmente nesse estudo, o município de São Paulo e suas diversas regiões, especialmente em razão da diversidade de 'realidades' que compõem o território paulistano, a qual é revelada, muitas vezes, por desigualdades na distribuição dos equipamentos sociais aos quais a população deve ter acesso e/ou por dificuldades de a eles recorrer.

Foram incluídas na pesquisa em foco as VIJs situadas em território com maior densidade populacional e que representam as cinco regiões do município de São Paulo. Com respaldo em consulta a estudos, pesquisas, indicadores sociais e censitários do município de São Paulo, destacam-se a seguir dados que retratam algumas características socioterritoriais das regiões nas quais estão inseridas as VIJs pesquisadas, com destaque para dados demográficos, população em situação de rua e equipamentos de assistência social. Embora as políticas sociais contemplem outras áreas, entre elas saúde e educação - que se evidenciaram na pesquisa realizada -, aqui é apresentada Serv. Soc. \& Saúde, Campinas, SP v. 13, n. 2 (18) p. 169-188 jul./dez. 2014 ISSN 1676-6806 
uma aproximação tão somente à Assistência Social, tendo em vista o recorte da interface entre essa política e a Justiça da Infância e da Juventude, escolhido para análise.

\section{Dados demográficos e divisão territorial}

No ano de 2010, conforme o Censo do Instituto Brasileiro de Geografia e Estatística (IBGE), o município de São Paulo contava com uma população de 11.253.503 habitantes, distribuída em um território de $1.521 .101 \mathrm{~km}^{2}$ (IBGE/Cidades/Censo 2010). De acordo com os dados disponíveis na Prefeitura Municipal de São Paulo (PMSP, 2013), o município é dividido em cinco regiões que somam 96 distritos, chegando-se ao cálculo populacional, estimado em 2011, de 4.001.384 na região Leste, 3.614.429 na região Sul, 2.220.900 na região Norte, 1.031.114 na Oeste, e 435.799 habitantes no Centro ${ }^{6}$.

A abrangência territorial de atendimento estabelecida para os foros regionais ${ }^{7}$, onde estão instaladas as VIJs, não segue o mesmo critério da divisão de distritos e regiões da administração municipal. Desse modo, por meio dos dados demográficos dos distritos que compõem as subprefeituras (PMSP, 2013a), tendo por referência o Censo do IBGE de 2010, foi realizada uma aproximação ao número de habitantes correspondente a cada VIJ, conforme informações a seguir:

- Foro Central: 19 distritos com 1.204.072 habitantes (engloba 5 subprefeituras das zonas Central, Leste, Oeste e Sul);

- Foro Regional I - Santana: 10 distritos com 1.143.542 habitantes (engloba 4 subprefeituras da zona Norte);

- Foro Regional II - Santo Amaro: 16 distritos com 2.553.804 habitantes (engloba 6 subprefeituras da zona Sul);

- Foro Regional III - Jabaquara: 3 distritos com 463.648 (engloba 3 subprefeituras da zona Sul):

- Foro Regional IV - Lapa: 11 distritos com 1.201.231 habitantes (engloba 5 subprefeituras das zonas Oeste e Norte):

\footnotetext{
${ }^{6}$ O total de habitantes constatado pelo IBGE/Censo 2010 (11.253.503) difere da soma desses números, pois esta, se refere à população estimada em 2011 (11.303.626).

${ }^{7}$ O levantamento dos distritos por VIJ foi baseado em consulta ao Guia de São Paulo MAPOGRAF/2012.

Serv. Soc. \& Saúde, Campinas, SP v. 13, n. 2 (18) p. 169-188 jul./dez. 2014 ISSN 1676-6806
} 
- Foro Regional V - São Miguel Paulista: 7 distritos com 950.132 habitantes (engloba 3 subprefeituras da zona Leste);

- Foro Regional VI - Penha de França: 4 distritos com 601.256 habitantes (engloba 2 subprefeituras da zona Leste);

- Foro Regional VII - Itaquera: 9 distritos com 1.304.054 habitantes (engloba 4 subprefeituras da zona Leste);

- Foro Regional VIII - Tatuapé: 4 distritos com 359.374 habitantes (engloba 2 subprefeituras da zona Leste);

- Foro Regional X - Ipiranga: 5 distritos com 885.829 habitantes (engloba 2 subprefeituras, uma da zona Sul e outra da zona Leste);

- Foro Regional XI - Pinheiros: 8 distritos com 586.561 habitantes (engloba 3 subprefeituras da zona Oeste).

A divisão de territórios e, com isso, a abrangência da população atendida pelos serviços públicos municipais de responsabilidade do Poder Executivo municipal e pelo Poder Judiciário Estadual evidenciam uma dicotomia relevante, especialmente observada na região Central (para a PMSP, 435.799 habitantes, e para a VIJ Central, 1.204.072 habitantes). São variações entre os serviços que podem resultar em dificuldades para a articulação da rede socioassistencial e para o acesso dos cidadãos usuários aos recursos que dela fazem parte, pois exigem deles uma mobilidade nem sempre conciliável entre tempo, recursos financeiros para transporte, percurso e outras atividades de seu cotidiano, como o trabalho.

A abrangência das VIJs apresenta proporções diferentes na extensão territorial e no número de distritos, o que em alguns casos diferencia significativamente a média de habitantes atendidos e o número de equipamentos/recursos sociais disponíveis por região. A VIJ Central tem uma área estendida que abrange territórios das regiões Oeste, Sul e Leste e, quando necessário, reporta-se a cinco subprefeituras também de regiões diferentes. A maioria das VIJs engloba distritos que correspondem a duas ou mais subprefeituras, especialmente a de Santo Amaro, que atinge seis delas. São aspectos que possivelmente exigem das equipes do Judiciário uma atenção maior ao interrelacionamento com serviços/equipamentos sociais diversos no encaminhamento de situações atendidas (caso das audiências concentradas), considerando que tais equipamentos têm como referência a divisão territorial da administração municipal. 


\section{População em situação de rua}

Aspectos sociais revelados na pesquisa, sobre as pessoas destituídas do poder familiar, evidenciam que significativa parcela delas vive em situação de rua (19\%), bem como apresenta algum grau de dependência química (24\%), dos quais $8 \%$ se referem ao crack, $11 \%$ a drogas sem especificação da substância, e 5\% ao álcool.

São informações que se destacam também nos dados demográficos do município de São Paulo, que recenseou em 2011 um total de 14.478 indivíduos em situação de rua (6.765 na rua e 7.713 em centros de acolhida), distribuídos em todas as regiões da cidade (PMSP, 2013a).

A menor incidência de indivíduos em situação de rua está nas zonas Oeste $(4,7 \%)$ e Norte $(7,1 \%)$. A região Central concentra mais da metade dessa população (55,3\%). Se considerados os indivíduos recenseados nos centros de acolhida, 73,8\% (5.694) encontram-se na área central, o que está relacionado ao maior índice de pessoas em situação de rua e também de oferta de vagas dessa natureza na região.

Em relação aos indivíduos em situação de rua, o Censo especificou a análise dessa área de maior concentração, considerando que em dez distritos do município que, de acordo com a divisão administrativa no ano de sua realização, compunham a zona Central (Sé, República, Pari, Brás ${ }^{8}$, Cambuci, Liberdade, Consolação, Bela Vista, Santa Cecília e Bom Retiro), estão 64\% dessa população (4.319), incluindo a que vive nos logradouros conhecidos como "cracolândia".

São indivíduos em sua maioria do sexo masculino (75,9\%). Quase metade $(48,8 \%)$ é nativa do estado de São Paulo, e dos migrantes de outros estados da Federação, destacam-se os de Bahia, Pernambuco e Minas Gerais.

Nessa população, identificaram-se grupos familiares em apenas 3,6\% dos pontos recenseados. Há mais mulheres em situação de rua na região central (505), comparando à somatória de outras regiões (331), e 28 casos de gravidez entre elas.

Do total de indivíduos recenseados no distrito de Santa Cecília, 62\% encontravam-se na região conhecida como "cracolândia". Nessa localidade, a maioria é do sexo masculino $(78,5 \%)$ e um pouco mais da metade é de cor negra $(52,4 \%)$.

\footnotetext{
8 O referido Censo considerou Pari e Brás como pertencentes à região Central (provavelmente considerando o Centro expandido), embora estejam localizados na região Leste. Serv. Soc. \& Saúde, Campinas, SP v. 13, n. 2 (18) p. 169-188 jul./dez. 2014 ISSN 1676-6806
} 


\section{Vulnerabilidade social}

Considerando que a pesquisa nos autos processuais constatou que a quase totalidade das pessoas destituídas do poder familiar vive em situação de pobreza ou de miséria ${ }^{9}$, apresentam-se aqui informações sobre a vulnerabilidade social no município de São Paulo, tomando por referência o Índice Paulista de Vulnerabilidade Social (IPVS), desenvolvido pela Fundação Seade (SEADE/IPVS, 2010), que, com base no censo demográfico do ano correspondente, classificou os setores censitários em sete grupos de vulnerabilidade social (no caso do município de São Paulo, em seis grupos) ${ }^{10}$.

Nesse índice, foi associada à dimensão socioeconômica (renda domiciliar per capita, rendimentos médios das mulheres responsáveis pelo domicílio, percentual de domicílios com renda per capita até meio salário mínimo, percentual de domicílios com renda per capita até um quarto do salário mínimo, percentual de pessoas alfabetizadas responsáveis pelo domicílio) a demográfica (percentual de pessoas responsáveis pelo domicílio com 10 a 29 anos, percentual de mulheres responsáveis pelo domicílio com 10 a 29 anos, idade média do responsável pelo domicílio, percentual de crianças de 0 a 5 anos).

A análise das condições de vida dos habitantes do município de São Paulo, constante desse estudo, mostra que

[...] a renda domiciliar média era de $\mathrm{R} \$ 3.537$, sendo que em $13 \%$ dos domicílios não ultrapassava meio salário mínimo per capita. Em relação aos indicadores demográficos, a idade média dos chefes de domicílios era de 47 anos e aqueles com menos de 30 anos representavam $14,1 \%$ do total. Dentre as mulheres responsáveis pelo domicílio, 14,2\% tinham até 30 anos, e a parcela de crianças com menos de seis anos equivalia a 7,7\% do total da população (SEADE/IPVS-2010a).

Os resultados do IPVS-2010 apontam que 70\% da população do município residiam em áreas de baixíssima, muito baixa ou de baixa vulnerabilidade. Dos $30 \%$ da população que residia em áreas de média, alta e muito alta vulnerabilidade, a renda domiciliar per capita era abaixo de um salário mínimo, sendo que foram apurados

\footnotetext{
${ }^{9}$ Em relação a trabalho, por exemplo, os maiores índices foram de 26\% no trabalho informal; 20\% sem qualquer trabalho; 9\% cumprindo pena de prisão (PESQUISA DPF, 2014).

${ }^{10}$ Grupo 1 - vulnerabilidade baixíssima: famílias jovens, adultas e idosas e nível socioeconômico muito alto; grupo 2 - vulnerabilidade muito baixa: famílias adultas e idosas e nível socioeconômico médio; grupo 3 - vulnerabilidade baixa: famílias jovens e nível socioeconômico médio; grupo 4 vulnerabilidade média: famílias adultas e idosas e nível socioeconômico baixo; grupo 5 - vulnerabilidade alta: famílias jovens em setores urbanos e nível socioeconômico baixo; grupo 6 - vulnerabilidade muito alta: famílias jovens residentes em aglomerados subnormais e nível socioeconômico baixo.
}

Serv. Soc. \& Saúde, Campinas, SP v. 13, n. 2 (18) p. 169-188 jul./dez. 2014 ISSN 1676-6806 
22,4\% de domicílios com renda per capita de até um quarto do salário mínimo e 86,2\% quando se tratava dos de até meio salário mínimo. Também, quando se tratava de mulheres com menos de 30 anos de idade responsáveis pelo domicílio, a média de renda era menor do que um salário mínimo, situadas nos grupos de média, alta e muito alta vulnerabilidade. Nos grupos considerados de alta e muito alta vulnerabilidade, verificase um maior número de crianças com menos de 6 anos de idade.

O georreferenciamento do IPVS em 2010 no município de São Paulo evidenciou concentração de áreas correspondentes ao grupo de baixíssima vulnerabilidade em distritos circunvizinhos da zona Oeste (Alto de Pinheiros, Pinheiros, Morumbi Perdizes, Jardim Paulista, Itaim Bibi), Sul (Moema e Vila Mariana) e Centro (Consolação e Bela Vista).

$\mathrm{Na}$ zona Norte há distritos característicos de vários grupos. No grupo de vulnerabilidade muito baixa encontram-se Santana, Tucuruvi, Mandaqui, Casa Verde, Limão, Freguesia do Ó, Vila Guilherme e Vila Medeiros. O distrito de Vila Maria apresenta características dos grupos de vulnerabilidade muito baixa e baixa e focos de vulnerabilidade alta e muito alta. Em Brasilândia, Jaraguá, Perus e Anhanguera observam-se grupos diversificados com incidência de vulnerabilidade média, alta e muito alta. Tremembé e Jaçanã, embora com áreas extensas do grupo de muito baixa vulnerabilidade, apresentam áreas entre média, alta e muito alta vulnerabilidade.

A zona Central apresenta características dos grupos de vulnerabilidade muito baixa e baixa, mas há distritos em que predominam áreas do grupo de vulnerabilidade baixíssima, como Consolação e Bela Vista, conforme já apontado. Pontos de vulnerabilidade média, alta e muito alta são encontrados apenas no Bom Retiro (alta e muito alta), Sé (média e alta) e Cambuci (média).

Como observado anteriormente, a zona Oeste apresenta distritos de baixíssima vulnerabilidade. Dentre eles se destacam no Morumbi focos de vulnerabilidade muito alta. Nos demais distritos, há o predomínio de áreas de muito baixa vulnerabilidade: Barra Funda, Vila Leopoldina, Lapa, Butantã, Rio Pequeno, Vila Sônia, os dois últimos com pequenos focos de muito alta vulnerabilidade, e Vila Jaguará, onde se destaca também área significativa de alta vulnerabilidade. E dois deles, Raposo Tavares e Jaguaré, também com incidência de baixa vulnerabilidade e áreas do grupo de muito alta vulnerabilidade. 
A zona Sul, considerando sua ampla extensão, apresenta distritos bem distintos quanto à vulnerabilidade. Com grau baixíssimo estão Moema, Vila Mariana e Vila Andrade, todavia nesse último localiza-se também uma área de muito alta vulnerabilidade. Com característica de baixíssima e muito baixa vulnerabilidade, encontram-se Santo Amaro, Campo Belo e Saúde. Há distritos em que predominam áreas de muito baixa vulnerabilidade, como Ipiranga, Cursino, Jabaquara, Cidade Dutra, Campo Grande (com área de média vulnerabilidade) e Sacomã, o qual também apresenta área de alta e muito alta vulnerabilidade. Áreas diversificadas nos grupos de vulnerabilidade começam a ser encontradas nas extremidades como Campo Limpo, Capão Redondo, Jardim São Luís (com focos de alta e muito alta vulnerabilidade), Cidade Ademar e Pedreira (os dois distritos com focos de média, alta e muito alta vulnerabilidade). Quanto mais ao extremo da zona Sul, são identificadas áreas do grupo de média, alta vulnerabilidade, como Parelheiros, Marsilac e Grajaú, esse último apresentando também área de muito alta vulnerabilidade.

A zona Leste apresenta distritos (que vão da região próxima ao Centro até o distrito de Arthur Alvim, limite com o de Itaquera) em que predominam áreas de vulnerabilidade muito baixa. Em alguns deles também aparecem pontos de muito alta vulnerabilidade, como Sapopemba, São Mateus e Cidade Líder. À medida que se aproximam as extremidades, encontram-se distritos com graus de vulnerabilidade diversificados, e áreas de vulnerabilidade média e de vulnerabilidade alta ficam mais evidentes, como em Cidade Tiradentes, Guaianazes, Iguatemi, Itaim Paulista, José Bonifácio, Vila Curuçá e São Rafael. Nesse último distrito e no de Jardim Helena e de Vila Jacuí se destacam áreas de muito alta vulnerabilidade.

Esse estudo do IPVS confirma que as áreas de vulnerabilidade alta ou muito alta se ampliam à medida que se avança pelos territórios situados em regiões periféricas do município. Áreas em que os equipamentos e serviços que poderiam contribuir para acesso a condições de vida com dignidade, além de trabalho decente, se apresentam de maneira mais escassa. $\mathrm{Na}$ área central verificam-se focos desses índices de vulnerabilidade em distritos como Sé, Santa Cecília, Bom Retiro e Cambuci, que nas últimas décadas concentraram pontos de deterioração urbana, sem atenção especial do poder público, alguns deles com habitações subnormais e espaços de concentração de usuários e dependentes de crack, muitos acumulando vivência em situação de rua e em alguns casos sofrendo processos de degradação humana, denunciando o Serv. Soc. \& Saúde, Campinas, SP v. 13, n. 2 (18) p. 169-188 jul./dez. 2014 ISSN 1676-6806 
descompromisso do poder público com uma política social e econômica redistributiva e inclusiva.

Em todas essas cinco regiões localizam-se VIJs com autos de destituição do poder familiar pesquisados, portanto, envolvendo moradores de todas elas, já que o processo, via de regra, tramita no fórum que abrange o território de moradia dos envolvidos, neste caso, da mãe e/ou pai e, na ausência deles, geralmente no território de moradia de outros responsáveis pela criança, incluindo organizações como unidades de saúde onde a gestante dá à luz ou unidades de acolhimento institucional de crianças.

\section{Assistência social - Proteção Básica e Especial de Média e Alta Complexidade e a distribuição de equipamentos no Município}

A gestão e a execução da Política de Assistência Social no município de São Paulo não ocorrem de forma unilateral por meio do poder público local. De acordo com a legislação, as organizações do terceiro setor são parceiras do poder municipal na sua execução, e sua participação está legitimada na LOAS/SUAS:

Art. $1^{\circ}$ A assistência social, direito do cidadão e dever do Estado, é Política de Seguridade Social não contributiva, que provê os mínimos sociais, realizada através de um conjunto integrado de ações de iniciativa pública e da sociedade, para garantia de atendimento às necessidades básicas (LOAS, 1993, alterada pela Lei n. 12.435/2011, que insere o SUAS na LOAS).

A Política Nacional da Assistência Social (2004) confirma a possibilidade dessa parceria:

Os serviços de proteção social, básica e especial, voltados para a atenção às famílias deverão ser prestados, preferencialmente, em unidades próprias dos municípios, através dos Centros de Referência da Assistência Social básico e especializado. Os Serviços, programas, projetos de atenção às famílias e indivíduos poderão ser executados em parceria com as entidades não governamentais de assistência social, integrando a rede socioassistencial (BRASIL, PNAS, 2004).

A PNAS/2004 e o SUAS sinalizam para a gestão descentralizada da assistência social, articulada nas três instâncias de governo, cabendo à União a responsabilidade pela coordenação e pelas normas. A coordenação e a execução de programas de responsabilidade dos estados e municípios também estabelecem níveis de gestão, como: gestão inicial, gestão básica e gestão plena. Cada nível de gestão se responsabilizará pela organização do atendimento às demandas e deverá seguir alguns 
requisitos básicos, como: reformulação das leis de criação dos Conselhos de Assistência Social, regulamentação dos Fundos Municipais, elaboração dos planos municipais, implantação do CRAS e do CREAS, contratação de pessoal qualificado, entre outros.

A política define que os serviços, programas, projetos e benefícios apresentem como foco prioritário as famílias, seus membros e indivíduos, o território como base de organização desses serviços, e que as ações assistenciais sejam organizadas em níveis de proteção social: Proteção Social Básica e Proteção Social Especial.

As ações incluídas nesses níveis de proteção, de acordo com a Lei n.12.435 de 6 de julho de 2011, que altera a LOAS, poderão ser executadas em parcerias com organizações socioassistenciais dos municípios, seguindo as referências da vigilância social, a proteção social e a defesa social e institucional.

No que tange aos serviços socioassistenciais executados pelas organizações não governamentais, devem seguir as orientações, os objetivos, princípios e diretrizes da LOAS/SUAS e da PNAS/2004 e cuidar para que suas práticas sociais não sejam direcionadas por perspectivas assistencialistas e paternalistas, que desvinculam o cidadão de seus direitos, mantendo-o na condição de subalterno. Nesse sentido, essas organizações devem desenvolver ações para a promoção da cidadania, dos direitos sociais dos usuários apregoados pela LOAS/SUAS, e a supressão do assistencialismo. Essas organizações devem dispor de recursos humanos conforme definido pela NOBRH/SUAS-2006 (BRASIL. MDS/SAS, 2011) e a sociedade deve ter conhecimento dos serviços socioassistenciais que desenvolvem, cabendo aos conselhos gestores sua fiscalização, no sentido de controlar se a Política de Assistência Social está sendo efetivada, se as ações estão pautadas nos propósitos estabelecidos pela LOAS/SUAS, PNAS/2004. E, por fim, que cada organização tenha clareza do papel que desempenha no território, não assumindo responsabilidades que cabem ao Estado.

No município de São Paulo, observa-se significativa participação de organizações não governamentais que mantêm parceria com o órgão governamental responsável pela Política de Assistência Social. Elas desenvolvem serviços da proteção básica e da proteção social especial de média e alta complexidade.

Uma aproximação analítica territorial da rede socioassistencial de São Paulo, particularmente nas regiões abrangidas pela pesquisa em foco, possibilita identificar a constituição dessa rede nesses espaços socioterritoriais. 
Em relação aos serviços da proteção social básica ${ }^{11}$, o CRAS, enquanto serviço público municipal, está assim distribuído: 17 na Região Leste, 13 na Sul, 15 na Norte, 3 na Oeste e um na Central. Dos serviços de proteção básica administrados pelas organizações socioassistenciais que compõem a Rede de Proteção Social da Assistência Social da cidade de São Paulo, verifica-se representatividade dos CCAs em todas as regiões da cidade: Leste - 153; Sul - 151; Norte - 93; Oeste - 46; Centro 13.Já para os CJs, existe menor investimento nas zonas Oeste (5) e Centro (1), áreas em que, segundo o IPVS, predominam grupos de baixíssima e baixa vulnerabilidade. Nas demais regiões esse serviço está assim distribuído: Leste - 16; Sul - 37; Norte 25. Situação semelhante ocorre com os SASFs - que aparentam estar alcançando maior estruturação nas zonas Leste (24) e Sul (14), enquanto nas demais regiões são em menor número: Norte - 7; Oeste: 3; Centro - 1. Em relação aos NCIs, chama a atenção o número reduzido de serviços nas mesmas regiões, considerando o envelhecimento populacional, de modo geral: Oeste -2 ; Centro - 1; Norte - 15; Leste: 37; Sul: $34^{12}$.

Dos serviços de proteção especial, os CREAS estão assim distribuídos: Leste 4; Sul - 7; Norte - 7; Oeste - 1; Centro - 2. Além dos CREAS, se destacam nas regiões Central e Leste os serviços direcionados às pessoas em situação de rua, considerando que nessas localidades se concentram os maiores índices de indivíduos nessa condição, como já mencionado: Leste: 32; Centro: 45; Sul 9; Norte - 9; Oeste - 7.

Em relação a serviços que executam medidas socioeducativas destinadas ao adolescente em conflito com a lei, verifica-se significativa concentração nas duas regiões com maior densidade populacional: Leste - 19; Sul - 19. Nas demais regiões são assim distribuídos: Norte - 10; Oeste - 2; Centro - 2 .

Os dados referentes aos serviços de acolhimento institucional/abrigo de crianças e adolescentes revelam sua representatividade em todas as regiões da cidade, proporcionalmente ao número de habitantes em cada uma delas: Leste - 61; Sul - 31; Norte - 21; Oeste - 12; Centro - 7. Levanta-se aqui a hipótese de que essa compatibilidade poderia estar relacionada às disposições do Estatuto da Criança e do Adolescente - Lei Federal 8.069/1990 (BRASIL, 2010) e diretrizes do Plano Nacional de Promoção, Proteção e Defesa do Direito de Crianças e Adolescentes à Convivência

\footnotetext{
${ }^{11}$ CRAS - Centro de Referência da Assistência Social; CCA - Centro para Criança e Adolescentes; CJ - Centro para a Juventude; SASF - Serviço de Apoio Social à Família, e NCI - Núcleo de Convivência para Idosos.

${ }^{12}$ Não foram pesquisadas eventuais defasagens existentes entre equipamentos e demandas.
}

Serv. Soc. \& Saúde, Campinas, SP v. 13, n. 2 (18) p. 169-188 jul./dez. 2014 ISSN 1676-6806 
Familiar e Comunitária - PNCFC (BRASIL, 2006), para que crianças e adolescentes que necessitam desse atendimento não se distanciem de sua realidade de origem, com vistas a favorecer a manutenção de seus vínculos familiares e comunitários, bem como o acesso aos serviços da rede socioassistencial.

Os dados acima revelam diferenças na quantidade de convênios existentes em cada uma das regiões. Somando-se os dados sobre os serviços de proteção especial, verifica-se que na zona Leste existem 17 CRAS e quatro CREAS, para uma região de maior número de habitantes (4.001.384) na cidade de São Paulo e na qual, embora predominem territórios considerados de vulnerabilidade muito baixa segundo o IPVS, há também distritos com população dos grupos de média, alta e muito alta vulnerabilidade. Se comparada à zona Norte, que tem uma população de 2.220.900 habitantes, preponderância de territórios considerados de muito baixa vulnerabilidade e que conta com um total de 15 CRAS e sete CREAS, a zona Leste apresenta defasagem nos serviços de proteção básica e principalmente de proteção especial. Na zona Sul, a existência de 13 CRAS e sete CREAS também não contempla integralmente as necessidades da região, se considerada sua extensão territorial e uma população de 3.614.429 habitantes, e que os distritos mais ao extremo apresentam graus de vulnerabilidade médio, alto e muito alto.

Importante salientar que a execução dos programas de transferência de renda que integram a Política de Assistência Social se insere nos serviços dos CRAS, que, no município de São Paulo, entre outras atividades relacionadas à proteção social, realizam cadastramento de famílias de baixa renda e em situação de vulnerabilidade para acesso ao programa federal de transferência de renda denominado Bolsa Família. Este programa é direcionado a famílias que têm renda mensal de até meio salário mínimo por pessoa ou renda mensal total de até três salários mínimos, e estabelece condicionalidades nas áreas da educação e da saúde.

O CRAS também é o principal responsável pelo cadastramento de famílias em situação de vulnerabilidade social no programa municipal de transferência de renda Renda Mínima, instituído em São Paulo em 2001, bem como no programa Renda Cidadã, este criado pelo governo do estado de São Paulo em 2005 com objetivo de atender famílias com renda mensal familiar per capita de até meio salário mínimo nacional. Cabe ao município, quando adere a este programa, integrar as ações 
socioassistenciais nele previstas aos serviços de proteção social básica da assistência social.

\section{CONSIDERAÇÕES FINAIS}

De maneira geral, os dados descritos neste texto demonstram a existência de diferenças na distribuição dos serviços e dos equipamentos de proteção básica e especial ofertada nos territórios, o que leva à reflexão se o município vem seguindo as diretrizes da NOB/SUAS, norma que define as áreas caracterizadas como vulneráveis por meio de indicadores municipais combinados às estatísticas nacionais que, juntos, podem representar situações agravadas de vulnerabilidade social e de reprodução da pobreza, e exigem maior atenção do poder público no planejamento, na implementação e na gestão das políticas sociais. Nesse sentido, a execução de políticas sociais nos territórios, com a instalação de outros equipamentos sociais (para além de unidades de acolhimento institucional/abrigo para criança e adolescentes), com serviços e gestão compatíveis com a realidade e as necessidades sociais da população que neles vive, possivelmente contribuiria, dentre outros, com a redução dos índices desse acolhimento institucional. Em consequência, o afastamento e desvinculação de crianças com seus familiares em razão de expressões da questão social, que culmina na destituição do poder familiar conforme trata a pesquisa base deste texto, poderia ser evitada, e essa medida definitiva na vida de muitas crianças, mães e pais, de fato, seria aplicada apenas nos casos em que, comprovadamente, a pobreza e a miséria não sejam a justificativa da separação - ainda que, muitas vezes, não explícitas na sentença.

Um aspecto que se destaca no estudo se refere ao não investimento na articulação entre a operacionalização das ações da Justiça da Infância e da Juventude e a gestão da proteção social, particularmente da Assistência Social no território, a partir da distribuição da população, de suas demandas e necessidades, especialmente no que se relaciona à atenção às crianças e adolescentes. Considerando que a própria abrangência territorial de uma Vara da Infância e da Juventude difere significativamente da abrangência dos distritos e subprefeituras do município, as possibilidades de ações interdisciplinares e intersetoriais voltadas à proteção social das famílias e o direito de crianças e adolescentes com elas conviveram, em seu meio ambiente/comunidade de origem, ficam comprometidas. Assim, sintonizar essa abrangência se coloca como um dos investimentos necessários para contribuir com a garantia do direito da criança e do Serv. Soc. \& Saúde, Campinas, SP v. 13, n. 2 (18) p. 169-188 jul./dez. 2014 ISSN 1676-6806 
adolescente à convivência familiar e comunitária, preferencialmente em sua família e comunidade de origem.

Dessa maneira, a revisão da divisão territorial de atendimento à população (tanto da administração municipal como do Judiciário e demais organizações que compõem o Sistema de Garantia de Direitos) é fundamental para a efetivação da intersetorialidade entre políticas e serviços, um dos principais pressupostos da PNAS (2004), na perspectiva da gestão, em todos os níveis, com vistas à inclusão social.

\section{Referências bibliográficas}

BRASIL. Lei Federal n. 8.069/1990. Dispõe sobre o Estatuto da Criança e do Adolescente. São Paulo: SEJDC/CEDCA, 2012.

BRASIL. NOB/SUAS 2012. Brasília: MDS/SAS, 2012. Disponível em: $<$ http://www.mds.gov.br/assistenciasocial/secretaria-nacional-de-assistencia-socialsnas/cadernos/norma-operacional-basica-suas/norma-operacional-basicasuas/?searchterm=NOB\%20SUAS\%202012>. Acesso em: 20 dez. 2013.

BRASIL. PNAS. Política Nacional de Assistência Social. CNAS. Brasília: MDS, 2005. Disponível em: <http://www.mds.gov.br/assistenciasocial/arquivo/Politica\%20Nacional\%20de\%20Assi stencia\%20Social\%202013\%20PNAS\%202004\%20e\%202013\%20NOBSUASsem\%20marca.pdf>. Acesso em: 7. abr. 2013.

BRASIL. Orientações Técnicas: Centro de Referência Especializado de Assistência Social - CREAS. Brasília: MDS/SAS, 2011. Disponível em: $<$ http://www.mds.gov.br/assistenciasocial/secretaria-nacional-de-assistencia-socialsnas/cadernos/orientacoes-tecnicas-centro-de-referencia-especializado-de-assistenciasocial-creas-1/04-caderno-creas-final-dez.pdf>. Acesso em: 20 dez. 2013.

BRASIL. Lei n. 8.742, de 7 de dezembro de 1993. Alterada pela Lei n. 12.435/2011. Dispõe sobre a organização da Assistência Social e dá outras providências. 2011. Disponível em:

<http://www.mds.gov.br/assistenciasocial/arquivo/L8742_de\%201993_alterada\%20pela \%2012435_de_2011.pdf/view>. Acesso em: 7 abr. 2013.

BRASIL. NOB-RH/SUAS. Anotada e Comentada. Brasília: MDS/SAS, 2011. 
BRASIL. PNCFC. Plano Nacional de Promoção, Proteção e Defesa do Direito de Crianças e Adolescentes à Convivência Familiar e Comunitária. Brasília: CNAS/CONANDA, 2006.

IBGE. Censo Demográfico 2010. Características da População e dos Domicílios. Resultado do Universo. Rio de Janeiro, 2011. Disponível em: <http://www.ibge.gov.br/english/estatistica/populacao/censo2010/caracteristicas_da_po pulacao/resultados_do_universo.pdf>. Acesso em: 20 mar. 2013.

IBGE. Cidades/Censo $2010 . \quad$ Disponível em: $<$ http://cidades.ibge.gov.br/xtras/perfil.php?lang=\&codmun=355030\&search=saopaulo|sao-paulo>. Acesso em: 18 dez. 2013.

IBGE. Indicadores Sociais Municipais. Uma análise dos resultados do universo do Censo Demográfico 2010. Estudos \& Pesquisas. Informação demográfica e socioeconômica, n. 28. Rio de Janeiro, 2011. Disponível em: <http://www.ibge.gov.br/home/estatistica/populacao/censo2010/indicadores_sociais_m unicipais/indicadores_sociais_municipais.pdf>. Acesso em: 20 mar. 2013.

KOGA, D. Medidas de cidades: entre territórios de vida e territórios vividos. São Paulo: Cortez, 2003.

PESQUISA DPF. Realidade social, direitos e perda do poder familiar: desproteção social $\mathbf{x}$ direito à convivência familiar e comunitária. São Paulo: NEPPSF/UNICSUL, 2014. (digitalizado).

PMSP. Infocidade/2013. Disponível em: <http://infocidade.prefeitura.sp.gov.br/htmls/7_populacao_censitaria_e_projecoes_popu lac_2008_10489.html>. Acesso em: 18 dez. 2013.

PMSP. Censo da População em Situação de Rua do Município de São Paulo 2011/2012.

Disponível

em:

<http://www.prefeitura.sp.gov.br/cidade/secretarias/assistencia_social/observatorio_soci al/pesquisas/index.php? $\mathrm{p}=18626 \geq$. Acesso em: 6. nov. 2013.

PMSP. Dados demográficos dos distritos pertencentes às subprefeituras. Disponível em:

<http://www.prefeitura.sp.gov.br/cidade/secretarias/subprefeituras/subprefeituras/dados _demograficos/index.php?p=12758>. Acesso em: 9 set. 2013.

SEADE. IPVS Versão 2010 - Índice Paulista de Vulnerabilidade Social. Instituto do Legislativo Paulista - ILP, Assembleia Legislativa, Fundação Sistema Estadual de Serv. Soc. \& Saúde, Campinas, SP v. 13, n. 2 (18) p. 169-188 jul./dez. 2014 ISSN 1676-6806 
Análise de Dados - Seade, Secretaria de Planejamento e Desenvolvimento Regional do Governo do Estado de São Paulo. Disponível em: $<$ http://www.iprsipvs.seade.gov.br/view/pdf/ipvs/principais_resultados.pdf $>$. Acesso em: 28 ago. 2013.

SEADE. IPVS. Versão 2010a - Município de São Paulo. Disponível em: <http://www.iprsipvs.seade.gov.br/view/pdf/ipvs/mun3550308.pdf>. Acesso em 28 ago. 2013. 
Serv. Soc. \& Saúde, Campinas, SP v. 13, n. 2 (18) p. 169-188 jul./dez. 2014 ISSN 1676-6806 